Check for updates

Cite this: RSC Adv., 2019, 9, 26559

\title{
Photolysis of carboxymethylflavin in aqueous and organic solvent: a kinetic study $\dagger$
}

\author{
lqbal Ahmad, (D) a Tania Mirza, ${ }^{a}$ Syed Ghulam Musharraf, (D) ${ }^{b}$ Zubair Anwar, (D)*a \\ Muhammad Ali Sheraz, (D) a Sofia Ahmed, (D) a Muhammad Ahsan Ejaz ${ }^{a}$ \\ and Adeela Khurshid ${ }^{a}$
}

\begin{abstract}
This is the first study on the photolysis of carboxymethylflavin (CMF), an intermediate in the photolysis of riboflavin (RF). CMF is photodegraded by removal of side-chain to lumichrome (LC) in acid solution and to LC and lumiflavin (LF) in alkaline solution. It also undergoes alkaline hydrolysis to 1,2-dihydro-1methyl-2-keto-3-quinoxaline carboxylic acid (KA) and 1,2,3,4-tetrahydro-1-methyl-2,3-dioxoquinoxaline (DQ) by cleavage of isoalloxazine ring. CMF degrades to LC in organic solvents. The formation of LC in acid solution and organic solvents takes place by second-order reaction and those of LC, LF, KA and DQ in alkaline solution by first-order reactions. The values of second-order rate constants for the photolysis of CMF at pH 2.0 to 7.0 are in the range of 1.13 to $2.45 \mathrm{M}^{-1} \mathrm{~s}^{-1}$ and those of first-order rate constants $\left(k_{\text {obs }}\right)$ at $\mathrm{pH} 8.0-12.0$ from 1.53 to $4.18 \times 10^{-4} \mathrm{~s}^{-1}$ and for the formation of photoproducts from 0.37 to $16.6 \times 10^{-5} \mathrm{~s}^{-1}$. The photolysis of $\mathrm{CMF}$ is enhanced, with $\mathrm{pH}$, in the alkaline region since the excited state is sensitive to alkaline hydrolysis. The photolysis and fluorescence quantum yields of CMF in aqueous and organic solvents have been reported. CMF and photoproducts have been assayed spectrofluorimetrically. The mode of CMF photolysis is discussed.
\end{abstract}

Received 14th April 2019
Accepted 24th July 2019
DOI: 10.1039/c9ra02818h
rsc.li/rsc-advances
An important consideration in degradation of chemical and pharmaceutical compounds is the effect of solvent on the rates of reaction. ${ }^{30-35}$ Solvent polarity plays an important role in the stabilization of drug formulations to prolong their shelf-lives. ${ }^{36-40}$ The effect of solvent on the photolysis of $\mathrm{RF}^{\mathbf{5 , 1 6 , 4 1 - 4 4}} \mathrm{FMF}^{, 20,21,45}$ $\mathrm{LC}^{45}$ and other flavins ${ }^{\mathbf{4 6 - 4 8}}$ has been studied. The photo-dynamics aspects of RF have also been investigated. ${ }^{49}$ The photolysis of CMF in organic solvents needs to be investigated to determine the effect of solvent polarity on its degradation.

The present work involves a detailed kinetic study of photolysis of CMF in aqueous and organic solvents, characterize the photoproducts and evaluate the kinetics of its degradation reactions. The rate- $\mathrm{pH}$ profiles could provide information about the regions of minimum and maximum degradation of the compound. Attempts are made to correlate the kinetic parameters with solvent polarity and viscosity. The photochemical and fluorescence quantum yields of CMF in aqueous and organic solvents are determined. CMF and its photoproducts are assayed by a recently developed multicomponent spectrofluorimetric method. ${ }^{29}$ The mode of photodegradation reactions of CMF is discussed.

\section{Experimental section}

\section{Materials}

LC and LF were procured from Sigma. CMF was prepared by the method of Fukumachi and Sakurai. ${ }^{22}$ KA and DQ were ${ }^{b}$ HEJ Research Institute of Chemistry, University of Karachi, Karachi-75270, Pakistan $\dagger$ Electronic supplementary information (ESI) available. See DOI: 10.1039/c9ra02818h 
<smiles>Cc1cc2nc3c(=O)[nH]c(=O)nc-3n(C(O)C(O)C(O)C(O)CO)c2cc1C</smiles>

(1)<smiles>Cc1cc2nc3[nH]c(=O)[nH]c(=O)c3nc2cc1C</smiles>

(3)<smiles>Cc1cc2nc3c(=O)[nH]c(=O)nc-3n(CC(=O)O)c2cc1C</smiles>

(5)<smiles>Cc1cc2nc3c(=O)[nH]c(=O)nc-3n(CC=O)c2cc1C</smiles>

(2)<smiles>Cc1cc2nc3c(=O)[nH]c(=O)nc-3n(C)c2cc1C</smiles>

(4)<smiles>Cc1cc2nc(C(=O)O)c(=O)n(C)c2cc1C</smiles><smiles>Cc1cc2[nH]c(=O)c(=O)n(C)c2cc1C</smiles>

(6)

(7)

Fig. 1 Chemical structures of riboflavin (RF) and photoproducts.

prepared from RF by the methods of Surrey and Nachod ${ }^{50}$ and Miles et al., ${ }^{51}$ respectively. The side-chain of KA and DQ was cleaved by periodic acid ${ }^{51}$ oxidation. The compounds were purified by cellulose column chromatography using 1butanol-1 propanol-acetic acid-water $(50: 30: 2: 18, \mathrm{v} / \mathrm{v})$ as solvent system. ${ }^{18}$ All the reagents and solvents of the highest purity were procured from Merck \& $\mathrm{Co}$. The buffers used were citric acid- $\mathrm{Na}_{2} \mathrm{HPO}_{4}(\mathrm{pH} 2.5-8.0), \mathrm{H}_{3} \mathrm{BO}_{3}-\mathrm{KCl}-\mathrm{NaOH}$ (pH 9.010.0) and $\mathrm{Na}_{2} \mathrm{HPO}_{4}-\mathrm{NaOH}(\mathrm{pH} 11.0-12.0)$. The ionic strength was $0.001 \mathrm{M}$ in each case. 


\section{Precautions}

The photolysis of CMF, thin-layer chromatography and fluorimetric assay have been carried out in a dark chamber.

\section{Measurement of $\mathrm{pH}$}

All pH measurements were carried out with a digital $\mathrm{pH}$ meter (Model CP-501; sensitivity \pm 0.01 units, Poland) using a combination $\mathrm{pH}$ electrode. The calibration of the electrode was performed using buffer solutions of $\mathrm{pH} 4.0,7.0$ and 9.0.

\section{Measurement of UV-visible spectra}

The spectral measurements were carried out with ThermoScientific UV-visible spectrophotometer (Evolution 201) using quartz glass cells of $10 \mathrm{~mm}$ path length.

\section{Measurement of fluorescence}

The measurement of fluorescence of CMF and photoproducts was performed out at $25 \pm 1{ }^{\circ} \mathrm{C}$ using Jasco FP-8300 spectroflurimeter (Japan). The wavelengths used for the determination of CMF and photoproducts are given in Table 1.

The fluorescence intensity was measured in relative units. Pure $0.01 \mathrm{mM}$ solutions ( $\mathrm{pH}$ 6.5) of these compounds were used as standards.

\section{Light intensity measurement}

The intensity of the radiation source, a Philips HPLN $125 \mathrm{~W}$ high pressure mercury vapor lamp, was determined by ferrioxalate actinometry ${ }^{52}$ and a value of $1.12 \pm 0.08 \times 10^{17}$ quanta per s was obtained.

\section{Determination of quantum yields of photolysis}

The quantum yields $\left(\Phi_{\mathrm{PD}}\right)$ for the photochemical formation of LC in acid solution and organic solvents by second-order reaction and the photodegradation of CMF in alkaline solution by first-order reaction have been determined by the method of Zirak et al. ${ }^{53,54}$ and Tyagi and Penzkofer ${ }^{55}$ as follows.

\section{Formation of LC}

Reaction description. The reactions involved in the formation of LC by CMF are described by eqn (8)-(11) and eqn (12)(21) in Scheme 2 (see section on Mode of photolysis).

Experimental procedure. The amount of formed LC and the amount of absorbed excitation light by CMF during a certain

Table 1 Excitation and emission wavelengths for the determination of CMF and photoproducts

\begin{tabular}{lll}
\hline Compound & $\begin{array}{l}\text { Excitation wavelength } \\
\left(\lambda_{\text {ex }}\right) \mathrm{nm}\end{array}$ & $\begin{array}{l}\text { Emission wavelength } \\
\left(\lambda_{\text {em }}\right) \mathrm{nm}\end{array}$ \\
\hline CMF & 445 & 530 \\
LC & 356 & 478 \\
LF & 445 & 530 \\
KA & 364 & 443 \\
DQ & 332 & 420
\end{tabular}

period is determined and the quantum yield of LC is calculated using the equation.

$$
\Phi_{\mathrm{PL}}=\frac{N_{\mathrm{LC}}}{n_{\mathrm{ph} \text { abs }}}
$$

where, $N_{\mathrm{LC}}=$ number density of generated LC

$$
n_{\mathrm{ph} \mathrm{abs}}=\frac{I_{\mathrm{exc}} t_{\mathrm{exc}}}{h v_{\mathrm{exc}}} \alpha_{\mathrm{exc}}=\frac{I_{\mathrm{exc}} t_{\mathrm{exc}}}{h v_{\mathrm{exc}}} \sigma_{\mathrm{exc}}^{1}[\mathrm{CMF}]
$$

$n_{\text {ph abs }}\left[\mathrm{cm}^{-3}\right]=$ number density of CMF absorbed photons per $1 \mathrm{~cm}$ of sample length, $I_{\text {exc }}\left[\mathrm{W} \mathrm{cm}^{-2}\right]=$ excitation light intensity in watt per $\mathrm{cm}^{2}, t_{\text {exc }}[\mathrm{s}]=$ time duration of light exposure in seconds, $h[\mathrm{~J} \mathrm{~s}]=$ Planck constant, $\nu_{\mathrm{exc}}\left[\mathrm{s}^{-1}\right]=$ excitation light frequency, $h \nu_{\text {exc }}[\mathrm{J}]$ energy of an excitation photon, $\alpha_{\text {exc }}\left[\mathrm{cm}^{-1}\right]=$ absorption coefficient of CMF at excitation wavelength, $\sigma_{\text {exc }}=$ absorption cross-section of CMF at excitation wavelength.

HPLC-Tof-MS system. Samples were recorded on HPLC-TofMS system (Agilent 6230). RP-C8 column was used for separation $(1.0 \times 50 \mathrm{~mm}, 3.5 \mu \mathrm{m}$, Agilent ZORBAX Eclipse XDB columns - C18 column). The mass spectrometer with ESI source was set in the positive ion mode. An isocratic mobile phase that is $0.1 \%$ formic acid in both water (eluent $\mathrm{A}$ ) and methanol (eluent B) was used at a flow rate of $0.5 \mathrm{ml} \mathrm{min}^{-1}$ for $20 \mathrm{~min}$. Injection volume was $2 \mu \mathrm{L}$.

\section{Photodegradation of CMF}

Reaction description. The reactions involved in the photolysis of CMF are described by eqn (12)-(16) in Scheme 2 (see section on Mode of photolysis), followed by.

$$
{ }^{3}[\mathrm{CMF}] * \underset{\text { photolysis }}{\stackrel{\mathrm{H}^{+} / \mathrm{OH}^{-}}{\longrightarrow}} \mathrm{LC}+\mathrm{LF}+\text { further photoproducts }
$$

Experimental procedure. The amount of photodegraded CMF and the amount of absorbed excitation light by CMF during a certain period is determined. The quantum yield of CMF is calculated using the equation.

$$
\Phi_{\mathrm{PL}}=\frac{N_{\mathrm{CMF}}}{n_{\mathrm{ph} \mathrm{abs}}}
$$

where, $N_{\mathrm{CMF}}=$ number density of degraded CMF, $n_{\mathrm{ph} \text { abs }}=$ as given in eqn (23) in Scheme 2

Fluorescence quantum yield. The fluorescence quantum yield $\left(\Phi_{\mathrm{F}}\right)$ is the ratio of photons emitted through fluorescence to photons absorbed.

$$
\Phi_{\mathrm{F}}=\frac{\text { number of photons emitted through fluorescence }}{\text { number of photons absorbed }}
$$

It can be determined of a comparative method ${ }^{56}$ using standard samples of a compound whose $\Phi_{\mathrm{F}}$ is known. The standard and the test samples having identical absorbance at the same excitation wavelength are assumed to absorb same number of photons. Therefore, the ratio of integrated fluorescence intensities of the two solutes determined under identical conditions gives the ratio of values of the quantum yields. Since 
$\Phi_{\mathrm{F}}$ of the standard is known, the $\Phi_{\mathrm{F}}$ of test sample can be calculated.

The method involves the measurement of absorbance and the integrated fluorescence intensity (i.e. area of the fluorescence spectra) of the sample of the standard and the test samples. The integrated fluorescence intensity of the standard and the test samples are plotted against the absorbance of each sample. The gradients of the two plots are proportional to the quantum yields of the two compounds. The fluorescence quantum yield of the unknown is calculated from the product of the quantum yield of the standard and the quotient of the two gradients according to the following equation.

$$
\begin{aligned}
\Phi_{\mathrm{F}} & =\Phi_{\mathrm{s}}\left(\frac{A_{\mathrm{s}}}{A_{\mathrm{u}}}\right)\left(\frac{E_{\mathrm{u}}}{E_{\mathrm{s}}}\right)\left(\frac{\eta_{\mathrm{u}}}{\eta_{\mathrm{s}}}\right)^{2} \\
& =\Phi_{\mathrm{s}}\left(\frac{m_{\mathrm{u}}}{m_{\mathrm{s}}}\right)\left(\frac{\eta_{\mathrm{u}}}{\eta_{\mathrm{s}}}\right)^{2}
\end{aligned}
$$

where, $\Phi_{\mathrm{s}}=$ fluorescence quantum yield of the standard, $m=$ gradient of the plot of integrated fluorescence intensity against absorbance, $\eta=$ refractive index of the solvent, $A=$ absorbance of the solution at the fluorescence excitation wavelength (445 $\mathrm{nm}), E=$ integrated fluorescence intensity, subscripts "s" and "u" refer to the standard and unknown samples, respectively, RF with a $\Phi_{\mathrm{F}}$ value of 0.24 (ref. 57) has been used as a standard in this case.

\section{Thin-layer chromatography (TLC)}

CMF and its side-chain cleavage products (LC and LF) were detected using $250 \mu \mathrm{m}$ cellulose plates (Whatman CC41) and the solvent systems: (a) 1-butanol-1-propanol-acetic acid-water $(50: 30: 2: 18, \mathrm{v} / \mathrm{v})$ and (b) 1-butanol-acetic acid-water (40:10:50,v/v, organic phase). ${ }^{12}$

The isoalloxazine ring cleavage products of $\mathrm{CMF}$, i.e. KA and DQ, were detected using $250 \mu \mathrm{m}$ silica gel $\mathrm{G}$ plates and the solvent system (c) chloroform-acetic acid-pyridine $(50: 10: 10, \mathrm{v} / \mathrm{v}) .{ }^{27}$ The spots of all these products were located by their characteristic fluorescence on excitation at $366 \mathrm{~nm}$.

\section{Photodegradation of CMF}

A CMF solution $\left(5 \times 10^{-5} \mathrm{M}\right)$ was prepared at $\mathrm{pH}$ 2.0-12.0, using appropriate buffer, in a $100 \mathrm{ml}$ volumetric flask and placed in a thermostat bath maintained at $25 \pm 1{ }^{\circ} \mathrm{C}$ in the radiation chamber. It was irradiated with the Philips HPLN $125 \mathrm{~W}$ high pressure mercury vapor lamp (emission at 405 and $435 \mathrm{~nm}$, the later wavelength corresponding to the absorption maximum of CMF at $445 \mathrm{~nm}),{ }^{19,22,29}$ fixed horizontally at a distance of $25 \mathrm{~cm}$ from the center of the flask. The same procedure was used for photolysis of CMF in organic solvents. Samples of degraded solutions were subjected to TLC and assay at appropriate intervals.

\section{Assay of CMF and photoproducts}

Aqueous solution. The assay of CMF and photoproducts has been carried out by a recently developed and validated spectrofluorimetric method. ${ }^{29}$ Since the photoproducts of CMF are the same as those of its hydrolytic degradation (LC, LF, KA, DQ), the method can be conveniently used for determination of these compounds. It involves extraction of the photodegraded solutions of CMF with chloroform at $\mathrm{pH} 2.0$ to remove side-chain products, LC and LF, and their assay at 478 and $530 \mathrm{~nm}$, respectively. This is followed by adjustment of the $\mathrm{pH}$ of aqueous phase to 6.5 and assay of $\mathrm{CMF}$ and the isoalloxazine ring cleavage products, KA and DQ, at 530, 443 and $420 \mathrm{~nm}$, respectively.

Organic solvents. A $1 \mathrm{ml}$ aliquot of degraded solution of CMF was evaporated to dryness under reduced pressure and the residue dissolved in $10 \mathrm{ml}$ of $\mathrm{pH} 6.5$ citro-phosphate buffer. The solution was used for fluorimetric assay of CMF and LC at 530 and $478 \mathrm{~nm}$.

\section{Results and discussion}

\section{Absorption characteristics of CMF}

The UV-visible and IR spectra of CMF are shown in Fig. 2a and b, respectively. CMF exhibits absorption maxima at $223 \mathrm{~nm}$ (molar decadic extinction coefficient, $\varepsilon=24700 \mathrm{M}^{-1} \mathrm{~cm}^{-1}$ ), $266 \mathrm{~nm}\left(\varepsilon=27800 \mathrm{M}^{-1} \mathrm{~cm}^{-1}\right), 376 \mathrm{~nm}\left(\varepsilon=9000 \mathrm{M}^{-1} \mathrm{~cm}^{-1}\right)$ and $445 \mathrm{~nm}\left(\varepsilon=10200 \mathrm{M}^{-1} \mathrm{~cm}^{-1}\right)$ at $\mathrm{pH} 7.0$ (Fig. 2a). These values are similar to those of RF and FMF having the same nucleus and different side-chains. ${ }^{58}$ The FTIR spectrum of CMF shows peaks at $3250 \mathrm{~cm}^{-1}(\mathrm{NH}), 1650 \mathrm{~cm}^{-1}(\mathrm{C}=\mathrm{O}), 1580 \mathrm{~cm}^{-1}$
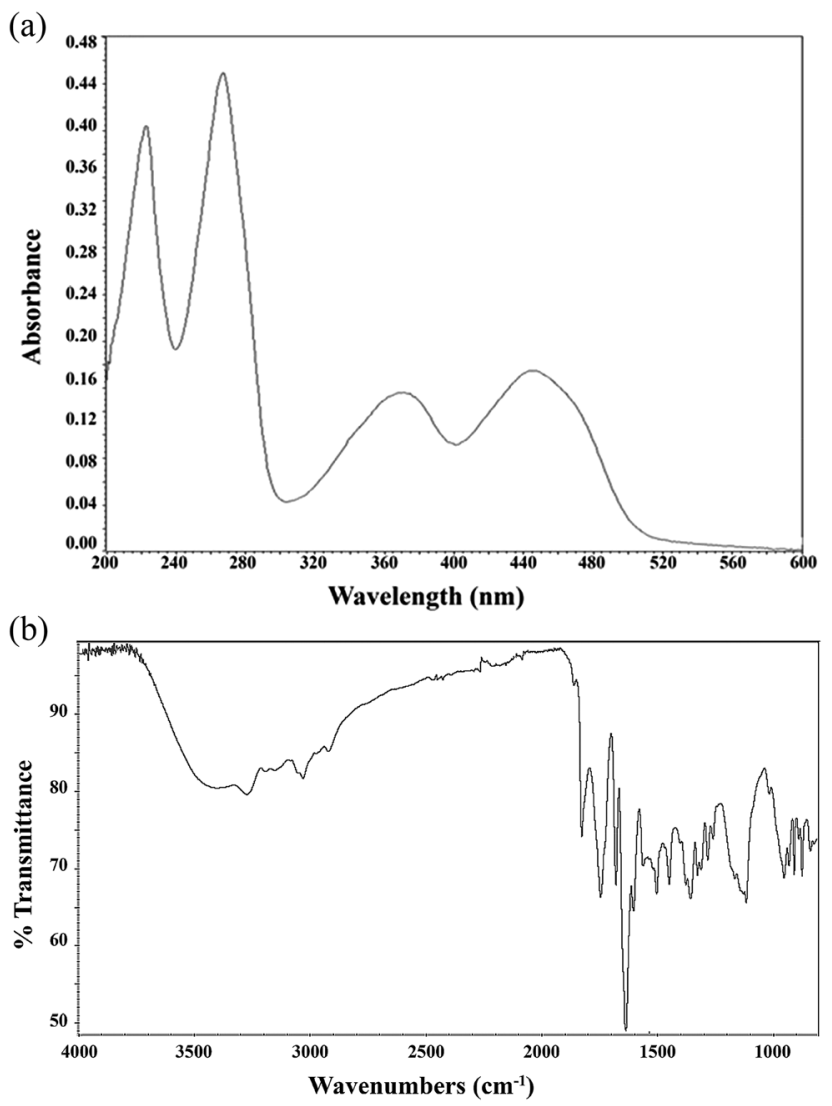

Fig. 2 (a) UV and visible absorption spectrum of $\mathrm{CMF}$ at $\mathrm{pH}$ 7.0. (b) FTIR spectrum of CMF. 
$(\mathrm{C}=\mathrm{C})$ and $1540 \mathrm{~cm}^{-1}(\mathrm{C}=\mathrm{N})$ (Fig. 2b). The broad absorption band in the $3300-2800 \mathrm{~cm}^{-1}$ region indicates hydrogen bonded $\mathrm{O}-\mathrm{H}$ stretching of the carboxylic group. This is further supported by the peaks at $1700 \mathrm{~cm}^{-1}$ and $1300 \mathrm{~cm}^{-1}$.

\section{Nature of photoproducts}

CMF was originally reported as a photoproduct in the photolysis of $\mathrm{RF}$ in alkaline solution in the presence of $\mathrm{H}_{2} \mathrm{O}_{2}$, along with LC and $\mathrm{LF}^{22,23}$ It has also been detected in the photolysis of $\mathrm{RF}^{12,13,51}$ and FMF and may be formed directly from $\mathrm{RF}^{23}$ or by the oxidation of FMF. ${ }^{21} \mathrm{LC}$ and LF are formed on the photolysis ${ }^{9,11,20,21}$ or hydrolysis of $\mathrm{FMF}^{17-19}$ and $\mathrm{CMF}^{29}$ in the alkaline solution.

It has been found that the formation of LC and LF takes place on the photolysis of CMF. Thus, a second route of the formation of LC and LF, in addition to that of FMF, in the photolysis of RF is through CMF. The other two products formed by isoalloxazine ring cleavage of CMF in alkaline solution are quinoxaline derivatives, KA and DQ. The formation of both of these products is enhanced with an increase in $\mathrm{pH}$ due to the hydrolysis of the isoalloxazine ring, ${ }^{29}$ as has previously been observed in the case of the hydrolysis of 9-methylisoalloxazine. ${ }^{27,28}$ The only product detected on the photolysis of CMF in organic solvents is LC. All these products have been identified on comparison of their characteristics fluorescence under UV light (CMF and LF, yellow green; LC, sky blue; KA and DQ, blue) and retention $\left(R_{\mathrm{f}}\right)$ values with those of the reference compounds using the solvent systems reported in the experimental section. The identification of photoproducts of CMF was necessary to confirm their presence in degraded solutions prior to the application of the spectrofluorimetric method for their assay during the photolysis reactions.

\section{Product composition}

The photolysis of CMF leads to the formation of LC, LF, KA and DQ in aqueous solution as described in the above section. The composition of these products at $50 \%$ degradation of CMF at $\mathrm{pH} 8.0-12.0$ is given in Table 2. The formation of LC in acid solution amounts to $50 \%$ and in the alkaline solution from 20 to $35 \%$ while the formation of $\mathrm{LF}$ in alkaline solution takes place to the extent of 8 to $13 \%$ of the degraded $\mathrm{CMF}$ in the $\mathrm{pH}$ range studied. The ring cleavage products, KA and DQ, occur to the extent of 5 to

Table 2 Product composition at $50 \%$ photolysis of $5.0 \times 10^{-5}$ M CMF solutions at $\mathrm{pH} 8.0-12.0$

\begin{tabular}{lllccl}
\hline $\mathrm{pH}$ & Time (min) & LC (\%) & LF (\%) & KA (\%) & DQ (\%) \\
\hline 8 & 75.3 & 34.8 & 8.4 & 4.8 & 2.0 \\
9 & 36.5 & 30.8 & 10.4 & 6.0 & 3.0 \\
10 & 30.8 & 26.2 & 11.0 & 7.8 & 4.8 \\
11 & 28.7 & 23.2 & 12.4 & 9.2 & 6.0 \\
12 & 27.6 & 20.2 & 13.0 & 10.4 & 6.4
\end{tabular}

$10 \%$ and 2 to $6 \%$, respectively. These results indicate that the formation of these photoproducts is gradually increased with $\mathrm{pH}$ due to the hydrolytic degradation of CMF which is accelerated in the presence of light. The decrease in the concentration of LC, with $\mathrm{pH}$, is due to its formation by an acid-catalyzed reaction. ${ }^{17}$

\section{Spectral characteristics of photolyzed solutions}

CMF has been found to undergo spectral changes during photolysis in acid and alkaline solutions (Fig. 3). These changes have been found to vary with $\mathrm{pH}$ and the loss of the molecule on degradation. A typical set of absorption spectra of CMF on degradation at $\mathrm{pH} 4.0$ is presented in Fig. 3a. It indicates the loss of peak at $445 \mathrm{~nm}$ and a shift towards $356 \mathrm{~nm}$ with concomitant increase in absorbance showing the formation of LC in acid solution. Another set of absorption spectra of CMF during photolysis at $\mathrm{pH} 11.0$ is shown in Fig. 3b. The loss of absorbance at $445 \mathrm{~nm}$ indicates the degradation of CMF and a prominent shift of the $374 \mathrm{~nm}$ peak towards $356 \mathrm{~nm}$ showing the formation of LC. The absorption spectrum of LF is similar to that of CMF and, therefore, it cannot be distinguished from CMF to indicate any spectral change. The disappearance of $445 \mathrm{~nm}$ peak indicates the cleavage of the isoalloxazine ring to form KA and DQ absorbing in the $300-400 \mathrm{~nm}$ region. ${ }^{27,28,59}$ Thus, the spectral changes on the photolysis of CMF at pH 11.0 indicate that the molecule is being transformed into its sidechain and ring cleavage products.

\section{Assay of CMF and photoproducts}

The photoproducts of CMF in acid (LC) and alkaline solution (LC, LF, KA and DQ) are same as those of the hydrolytic degradation reaction. However, the formation of LC and LF is increases in presence of light. Therefore, a single method can be applied to the determination of the products of hydrolytic and photolytic degradation. Recently, a spectrofluorimetric method has been developed and validated for the determination of CMF and its side-chain cleavage (LC and LF) and ring cleavage products (KA and DQ). ${ }^{29}$ The accuracy of the method has been reported to be within $1 \% .{ }^{29}$ This is used for the determination of CMF and photoproducts during photolysis. The results of the assay of these compounds on the photolysis of CMF for a typical reaction ( $\mathrm{pH} 10)$ are given in Table 3. These indicate an almost constant molar balance at various intervals showing the accuracy of the method. The assay data for the reactions carried out at $\mathrm{pH}$ 2.0-12.0 have been used to evaluate the kinetics of degradation of CMF.

\section{Kinetics of photolysis of CMF}

CMF undergoes photolysis to form LC in acid solution and LC, LF, KA and DQ in alkaline solution (Scheme 1).

The kinetics of these reactions has not so far been studied. A recent study ${ }^{29}$ has shown that CMF is degraded by hydrolysis to form the above mentioned compounds in aqueous solution. Considering the photolysis of CMF in acid solution to form LC by a second-order reaction $\left(k_{1}\right)$ and to form LC, LF, KA and DQ 


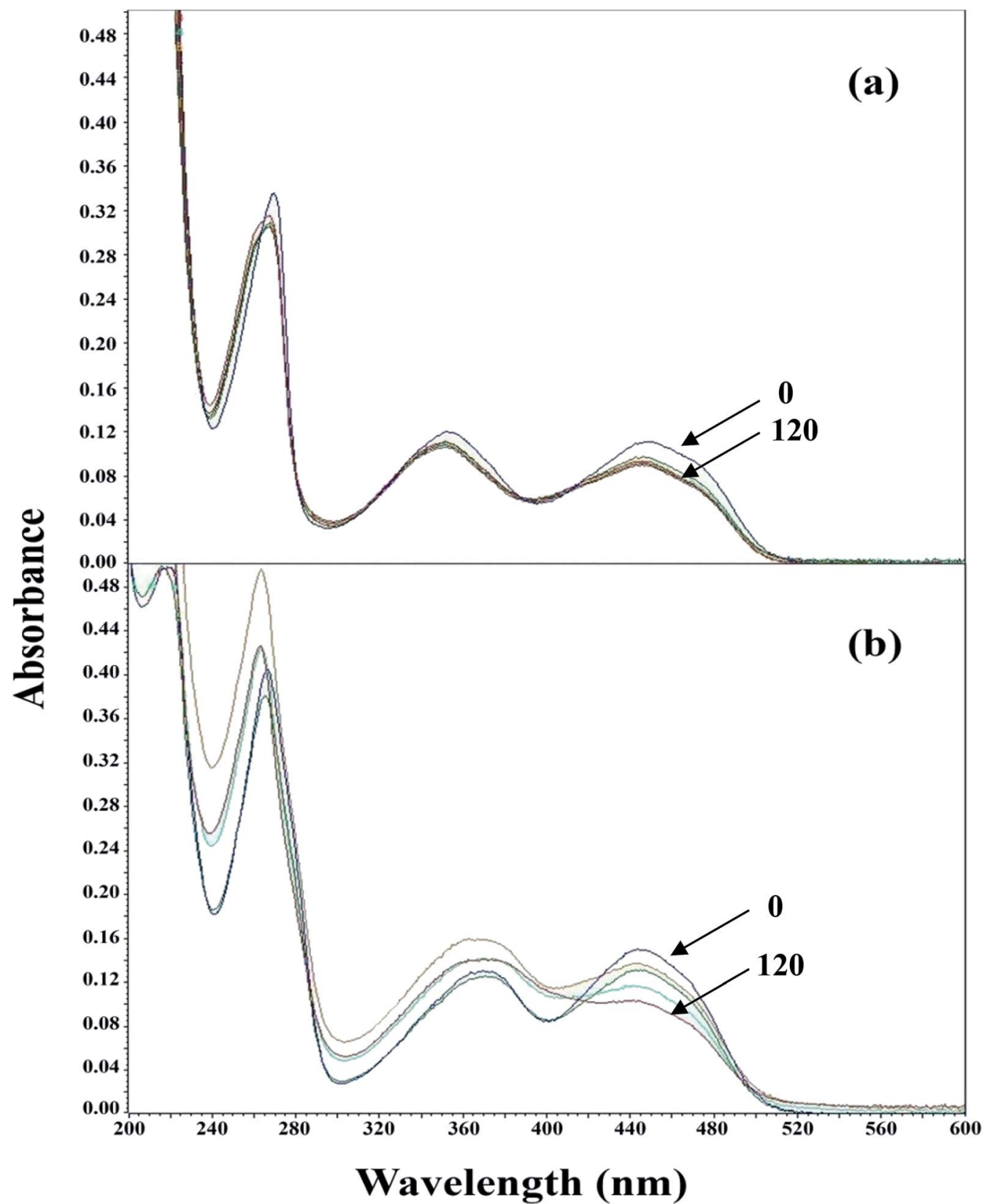

Fig. 3 Absorption spectra of CMF on photolysis at pH 4.0 (a), and at pH 11.0 (b). Times indicated are in min.

in alkaline solution by parallel first-order reactions, the rate constants, $k_{2}, k_{3}, k_{4}$ and $k_{5}$, can be calculated by the method of Frost and Pearson ${ }^{60}$ an applied previously to the photolysis of $\mathrm{RF}^{61}$
Photolysis of CMF in acid solution

$$
\frac{-\mathrm{d}[\mathrm{CMF}]}{\mathrm{d} t}=k_{1}[\mathrm{CMF}]^{2}
$$

Table 3 Photolysis of CMF at $\mathrm{pH}$ 10.0. Concentrations of CMF and photoproducts

\begin{tabular}{lllllll}
\hline Time $(\mathrm{min})$ & $\mathrm{CMF}\left(\mathrm{M} \times 10^{5}\right)$ & $\mathrm{LC}\left(\mathrm{M} \times 10^{5}\right)$ & $\mathrm{LF}\left(\mathrm{M} \times 10^{5}\right)$ & $\mathrm{KA}\left(\mathrm{M} \times 10^{5}\right)$ & DQ $\left(\mathrm{M} \times 10^{5}\right)$ & Total $\left(\mathrm{M} \times 10^{5}\right)$ \\
\hline 0 & 5.00 & - & - & - & 0.46 & 5.00 \\
15 & 2.38 & 0.91 & 0.85 & 0.85 & 0.51 & 5.03 \\
30 & 1.22 & 1.31 & 1.15 & 1.10 & 0.56 & 4.95 \\
45 & 0.59 & 1.43 & 1.28 & 1.18 & 0.62 & 5.02
\end{tabular}




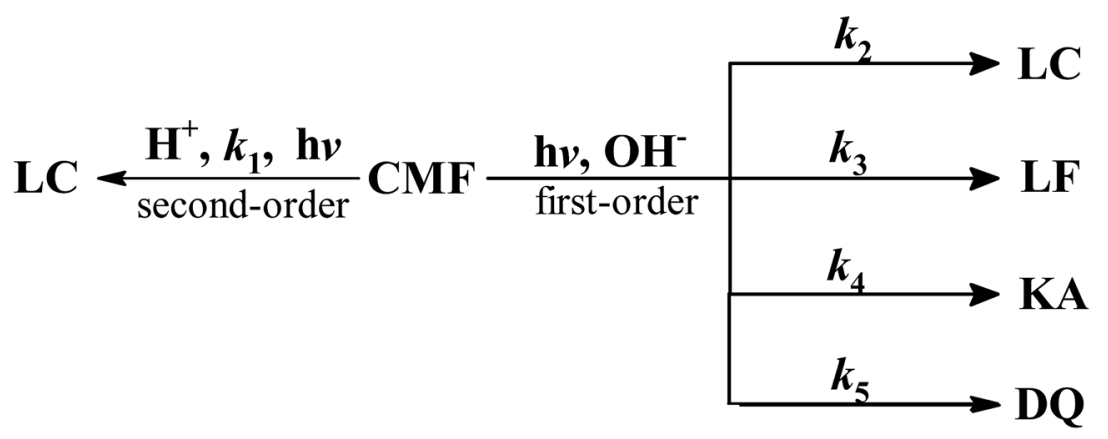

Scheme 1 Photolysis of CMF in acid and alkaline solution.

The rate constants, $k_{1}$, for second-order photolysis reactions of $\mathrm{CMF}$ in acid solution determined from slopes of inverse concentration $(1 / c)$ against time plots are given in Table 4 .

Photolysis of CMF in alkaline solution. If $A, U, V, W$ and $X$ are the corresponding concentrations of CMF, LC, LF, KA and DQ during degradation and $A_{\mathrm{o}}$ is initial concentration of CMF, the overall rate constant $\left(k_{\text {obs }}\right)$ can be written as:

$$
\frac{-\mathrm{d} A}{\mathrm{~d} t}=k_{2} A+k_{3} A+k_{4} A+k_{5} A=\left(k_{2}+k_{3}+k_{4}+k_{5}\right) A=k_{\mathrm{obs}} A
$$

Therefore

$$
k_{\mathrm{obs}}=k_{2}+k_{3}+k_{4}+k_{5}
$$

and

$$
\ln \frac{\left(A_{\mathrm{o}}\right)}{A}=k_{\mathrm{obs}} t
$$

or

$$
A=A_{\mathrm{o}} \mathrm{e}^{-k t}
$$

Considering the degradation of $A$ as a first-order reaction

$$
\frac{\mathrm{d} U}{\mathrm{~d} t}=k_{2} A=k_{2} A_{\mathrm{o}} \mathrm{e}^{-k t}
$$

and

$$
U=\frac{k_{2} A_{\mathrm{o}}}{k_{\mathrm{obs}}} \mathrm{e}^{-k t}+\text { constant }
$$

Table 4 Second-order rate constants $\left(k_{1}\right)$ and half-lives for the photolysis of CMF in acid solution

\begin{tabular}{lccc}
\hline $\mathrm{pH}$ & $k_{1}\left(\mathrm{M}^{-1} \mathrm{~s}^{-1}\right) \pm \mathrm{SD}$ & $t_{1 / 2}(\mathrm{~min})$ & $\Phi^{a}$ \\
\hline 2.0 & $1.13 \pm 0.01$ & 295.0 & 0.16 \\
3.0 & $4.20 \pm 0.05$ & 79.3 & 0.20 \\
3.5 & $8.05 \pm 0.09$ & 41.4 & 0.23 \\
4.0 & $10.85 \pm 0.11$ & 30.7 & 0.29 \\
4.5 & $6.04 \pm 0.07$ & 55.2 & 0.06 \\
5.0 & $2.75 \pm 0.03$ & 121.2 & 0.05 \\
6.0 & $1.99 \pm 0.02$ & 167.5 & 0.05 \\
7.0 & $2.45 \pm 0.02$ & 136.1 & 0.12
\end{tabular}

${ }^{a}$ It represents the quantum yields for the formation of LC, the major side-chain photoproduct. or

$$
\begin{aligned}
& U=U_{\mathrm{o}}+\left(k_{2} A_{\mathrm{o}} / k_{\mathrm{obs}}\right)\left(1-\mathrm{e}^{-k t}\right) \\
& V=V_{\mathrm{o}}+\left(k_{3} A_{\mathrm{o}} / k_{\mathrm{obs}}\right)\left(1-\mathrm{e}^{-k t}\right) \\
& W=W_{\mathrm{o}}+\left(k_{4} A_{\mathrm{o}} / k_{\mathrm{obs}}\right)\left(1-\mathrm{e}^{-k t}\right) \\
& X=X_{\mathrm{o}}+\left(k_{5} A_{\mathrm{o}} / k_{\mathrm{obs}}\right)\left(1-\mathrm{e}^{-k t}\right)
\end{aligned}
$$

If $U_{\mathrm{o}}=V_{\mathrm{o}}=W_{\mathrm{o}}=X_{\mathrm{o}}=0$, the equations can be expressed as

$$
\begin{aligned}
& V I U=k_{3} / k_{2} \\
& W / U=k_{4} / k_{2} \\
& X I U=k_{5} / k_{2}
\end{aligned}
$$

or

$$
U: V: W: X=k_{2}: k_{3}: k_{4}: k_{5}
$$

The concentrations of the photoproducts are in a constant ratio to each other. These are independent of time and the initial concentration of $\mathrm{CMF}$ and can be used to determine the rate constants for the individual reactions. The values of $k_{\text {obs }}$ for disappearance of CMF and $k_{2}, k_{3}, k_{4}$ and $k_{5}$ for formation of LC, LF, KA and DQ, respectively, at pH 8-12 are reported in Table 5 . These rate constants vary with $\mathrm{pH}$ as discussed in a later section. The sum of the individual rate constants for the formation of the photoproducts is almost equal to the values of the $k_{\text {obs }}$ for the photolysis of CMF at a particular $\mathrm{pH}$ (Table 5).

Photolysis of CMF in organic solvents. The photolysis of CMF in organic solvents has been found to follow second-order kinetics to form LC as observed in the case of FMF. ${ }^{20}$

$$
\mathrm{CMF} \underset{\text { second-order }}{\stackrel{h v, k_{6}}{\longrightarrow}} \mathrm{LC}
$$

It is similar to that of CMF in acid solution as described above. However, the rates of the reaction are lower than those observed in the acid solution. This is due to a change in the polarity of the medium. The second-order rate constants, $k_{6}$, for these reactions are reported in Table 6 . The values increase on increasing the polarity of solvent. 
Table 5 Apparent first-order rate constants $\left(k_{\mathrm{obs}}\right)$ for the photolysis of $\mathrm{CMF}$ at $\mathrm{pH}$ 8.0-12.0, and the rate constants for the formation of lumichrome (LC) $\left(k_{2}\right)$, lumiflavin (LF) $\left(k_{3}\right)$, keto acid (KA) $\left(k_{4}\right)$ and dioxo-quinoxaline (DQ) $\left(k_{5}\right)$, second-order rate constants $\left(k^{\prime}\right)$ for $O H^{-}$ion catalyzed reaction and quantum yields of photolysis $(\Phi)$

\begin{tabular}{|c|c|c|c|c|c|c|c|c|}
\hline $\mathrm{pH}$ & $k_{\mathrm{obs}} \times 10^{4}\left(\mathrm{~s}^{-1}\right) \pm \mathrm{SD}$ & $t_{1 / 2}(\min )$ & $k_{2} \times 10^{4}\left(\mathrm{~s}^{-1}\right)$ & $k_{3} \times 10^{4}\left(\mathrm{~s}^{-1}\right)$ & $k_{4} \times 10^{4}\left(\mathrm{~s}^{-1}\right)$ & $k_{5} \times 10^{4}\left(\mathrm{~s}^{-1}\right)$ & $k^{\prime}\left(\mathrm{M}^{-1} \mathrm{~s}^{-1}\right)$ & $\Phi^{a}$ \\
\hline 8 & $1.53 \pm 0.06$ & 75.3 & 0.76 & 0.36 & 0.23 & 0.18 & 153.0 & 0.32 \\
\hline 9 & $3.07 \pm 0.12$ & 36.5 & 1.08 & 0.91 & 0.66 & 0.42 & 31.7 & 0.34 \\
\hline 10 & $3.75 \pm 0.15$ & 30.8 & 1.47 & 1.10 & 0.70 & 0.48 & 3.75 & 0.36 \\
\hline 11 & $4.01 \pm 0.14$ & 28.7 & 1.63 & 1.13 & 0.75 & 0.50 & 0.40 & 0.39 \\
\hline 12 & $4.15 \pm 0.16$ & 27.6 & 1.67 & 1.15 & 0.80 & 0.53 & 0.04 & 0.41 \\
\hline
\end{tabular}

${ }^{a}$ It represents the overall quantum yields for the photolysis of CMF.

\section{pH effect}

$\mathrm{CMF}$ is sensitive to $\mathrm{pH}$ in the presence or absence of light and undergoes degradation to give LC in acid solution and LC, LF, KA and DQ in alkaline solution. The kinetic results (Table 2) indicate that $\mathrm{CMF}$ is more labile to side-chain cleavage than the ring cleavage. The $k-\mathrm{pH}$ profiles for photolysis of CMF in acid and alkaline regions have been determined. A plot of $k_{1}$ for the photolysis of CMF in acid region versus $\mathrm{pH}$ is shown in Fig. 4. The rate of the reaction is slow in the $\mathrm{pH}$ range 2 to 3 due to protonation of the molecule $(\mathrm{N}-10)$ as observed in the case of $\mathrm{RF}$ $\left(\mathrm{p} K_{\mathrm{a}} 1.7\right)^{13,62}$ and is then increased up to $\mathrm{pH} 4$. Above this value a rapid decrease in the rate up to $\mathrm{pH} 6$ is observed. This is similar to that of the photolysis of FMF ( $\left.K_{\mathrm{a}} 3.5\right)^{63}$ which also have the highest rate around $\mathrm{pH} 4$ in the acid region. ${ }^{21}$ The decrease in the rate above $\mathrm{pH} 4$ can be explained on the basis of redox potentials of flavins which have lowest values in the $\mathrm{pH}$ range of 5 to 6 (e.g. $\mathrm{RF}-0.117 \mathrm{~V}$ at $\mathrm{pH} 5.0,-0.208$ at $\mathrm{pH} 7.0) .{ }^{39}$ This would slow down the photoreduction of CMF and lead to a decrease in rate in this region. The values of $k_{1}$ for the photolysis of $\mathrm{CMF}$ in acid solution are in the range of 1.13 to $2.45 \mathrm{M}^{-1} \mathrm{~s}^{-1}$ at pH 2 to 7 (Table 4). Flavins are known to degrade by photoreduction process. ${ }^{\mathbf{4 2 4 , 2 5}}$

The $k$-pH profile for photolysis of CMF in alkaline region is shown in Fig. 5. It represents a steep curve in the pH range 8-10 followed by a decline in rate upto $\mathrm{pH} 12$ as a result of hydrolytic degradation. The lowering of rate above $\mathrm{pH} 10$ appears to be due to the ionization of the $\mathrm{N}_{3}-\mathrm{H}$ group $\left(\mathrm{p} K_{\mathrm{a}} 10.2\right)^{62}$ of the isoalloxazine nucleus. This is in accordance with the photolysis behavior of RF which is also less susceptible to degradation in the $\mathrm{pH}$ range $10.0-12.0 .{ }^{13}$ The increase in the rate in alkaline region is probably due to the fact that the flavin triplet state exists in a bent, diradical form which is more sensitive to alkaline hydrolysis. ${ }^{\mathbf{1 1}}$ At pH 8 and above CMF undergoes isoalloxazine ring cleavage to form KA and DQ and, therefore, the values of $k_{\mathrm{obs}}$ are further increased with $\mathrm{pH}$ in this region as observed in the case of $\mathrm{FMF}^{19}$ and 9-methylisoalloxazine. ${ }^{27,28}$ All the products of alkaline photolysis of CMF (LC, LF, KA, DQ) are formed by parallel first-order kinetics and the rates of these reactions are in the range of $0.18-1.67 \times 10^{-4} \mathrm{~s}^{-1}$ at $\mathrm{pH} 8.0-12.0$ (Table 5). The rate-pH profiles for formation of LC, LF, KA and DQ in the alkaline region are similar to that of the degradation of CMF (Fig. 6). However, the individual rates of formation of these products are lower than that of the overall loss of CMF. The ratio of the rate constants for the formation of side-chain cleavage products, LC and $\operatorname{LF}\left(k_{2}\right.$ and $\left.k_{3}\right)$ and those of the formation of ring cleavage products, KA and DQ $\left(k_{4}\right.$ and $\left.k_{5}\right)$ on the photolysis of $\mathrm{CMF}$ at $\mathrm{pH} 12$ is 6.8 : 3.2.

\section{Hydroxyl ion catalysis}

In alkaline solution the photolysis of CMF is catalyzed by $\mathrm{OH}^{-}$ ions. In order to evaluate the effect of $\mathrm{OH}^{-}$ions on the rate of photolysis of CMF, the $\log k_{\mathrm{obs}}$ values were plotted against $\mathrm{pH}$ which showed a biphasic linear relation (Fig. 7). The values of second-order rate constants $\left(k^{\prime}\right)$ for the $\mathrm{OH}^{-}$ion catalyzed reactions at various $\mathrm{pH}$ values are reported in Table 5 . The slight deviation in rate constants at 10.5 to 12.0 is due to the involvement of the $\mathrm{N}_{3}$-anion of CMF with a $\mathrm{p} K_{\mathrm{a}}$ value similar to that of RF (10.2) ${ }^{62}$ and being less sensitive to photolysis.

\section{Effect of solvent}

Dielectric constant. The photolysis of CMF in organic solvents follows second-order kinetics and the values of the rate constants

Table 6 Second-order rate constants $\left(k_{6}\right)$ for the photolysis of CMF in organic solvents and water

\begin{tabular}{|c|c|c|c|c|}
\hline Solvent & Acceptor number & Dielectric constant $(\varepsilon)$ & $\begin{array}{l}\text { Inverse viscosity } \\
(\mathrm{mPa} \mathrm{s})^{-1}\left(25^{\circ} \mathrm{C}\right)\end{array}$ & $k_{6}\left(\mathrm{M}^{-1} \mathrm{~s}^{-1}\right)$ \\
\hline Ethyl acetate & 17.1 & 6.02 & 2.268 & 0.98 \\
\hline 1-Butanol & 36.8 & 17.8 & 0.387 & 1.15 \\
\hline 1-Propanol & 37.3 & 20.1 & 0.514 & 1.20 \\
\hline Acetone & 12.5 & 20.7 & 0.330 & 1.23 \\
\hline Ethanol & 37.1 & 24.3 & 0.931 & 1.26 \\
\hline Methanol & 41.3 & 32.6 & 1.828 & 1.42 \\
\hline Acetonitrile & 18.9 & 38.5 & 2.898 & 1.56 \\
\hline Water & 54.8 & 78.5 & 1.123 & 2.45 \\
\hline
\end{tabular}




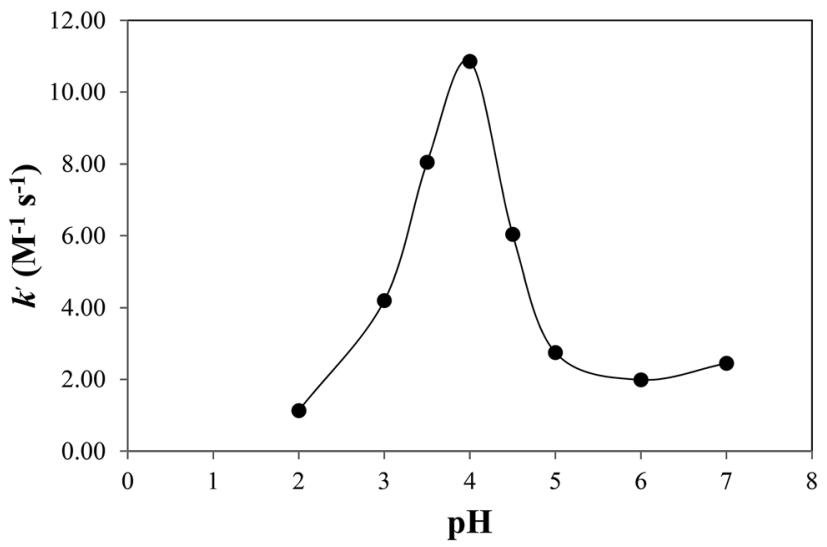

Fig. $4 \quad k_{1}-\mathrm{pH}$ profile for photolysis of $\mathrm{CMF}$ at $\mathrm{pH}$ 2.0-7.0.

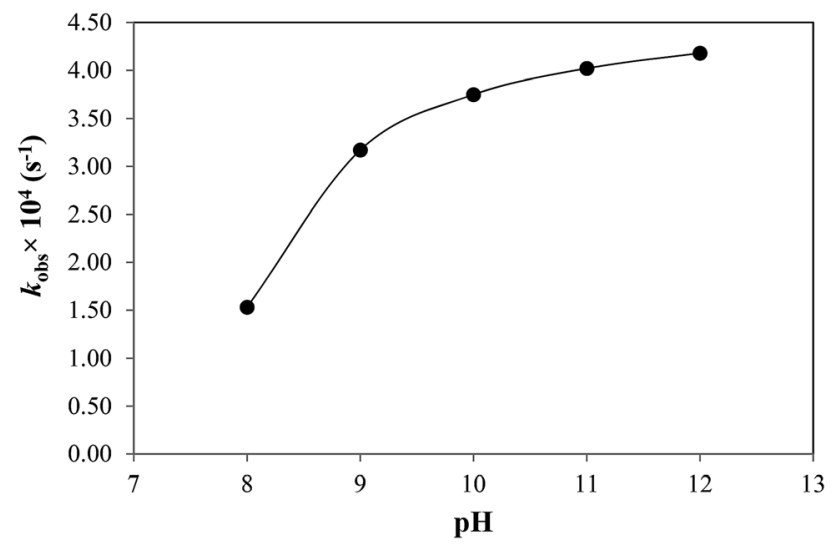

Fig. $5 k_{\text {obs }}-\mathrm{pH}$ profile for the photolysis of $\mathrm{CMF}$ at $\mathrm{pH}$ 8.0-12.0.

$\left(k_{6}\right)$ are given in Table 6 . A plot of $k_{6}$ versus relative dielectric constant $(\varepsilon)$ of the solvents is shown in Fig. 8. The increase in rate with $\varepsilon$ indicates that the rate of reaction is controlled by the polarity of the solvent. This is probably due to the existence of a dipolar species in

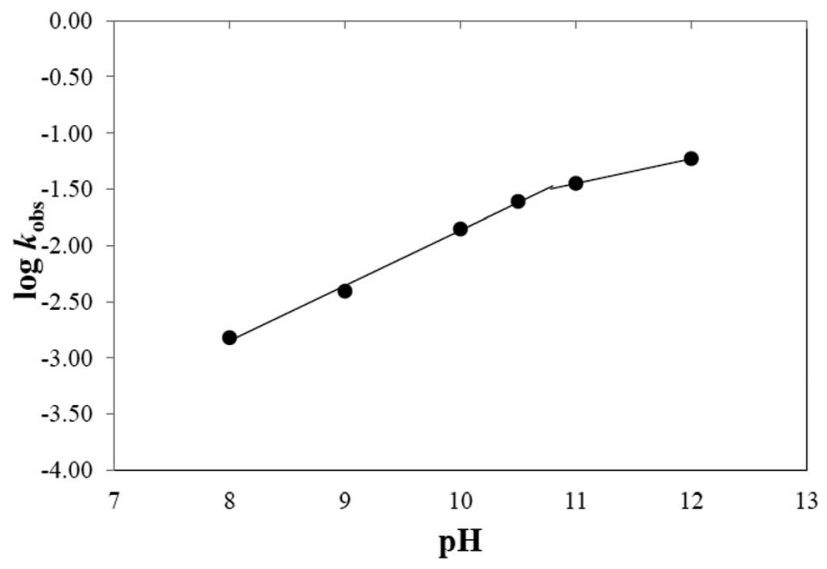

Fig. $7 \log k_{\text {obs }}$ against $\mathrm{pH}$ plot for the photolysis of CMF in alkaline solution.

photoreduction of flavins in aqueous and organic solvents as proposed by Ahmad and Tollin. ${ }^{48}$ The reactivity of this intermediate depends on the extent of solvent interaction. This implies that if the polarity of the intermediate state is greater than that of the reactant it would lead to an increase in rate with an increase in relative dielectric constant of the solvent as reported in the case of $\mathrm{RF}^{\mathbf{1 6}}$ and FMF. $^{20}$

The effect of solvent on the rate of a reaction can also be considered in terms of the acceptor number (AN) which determines the ability of a solvent to take shares in electron pairs from suitable donors. ${ }^{64}$ When the $\ln \left(k_{6}\right)$ values for the photolysis of CMF are plotted against the AN of highly structured solvents (i.e. above 25), a linear relation is observed (Fig. 9). The AN is considered as a measure of the reactivity of a species in different solvents. ${ }^{65}$ The solvent dielectric constant is considered as a good indicator for prediction of the extent of solutesolvent interaction.

Viscosity. The rate of a reaction may be influenced by the viscosity of the solvent as observed in the case of $\mathrm{RF}^{\mathbf{1 6}}$ and

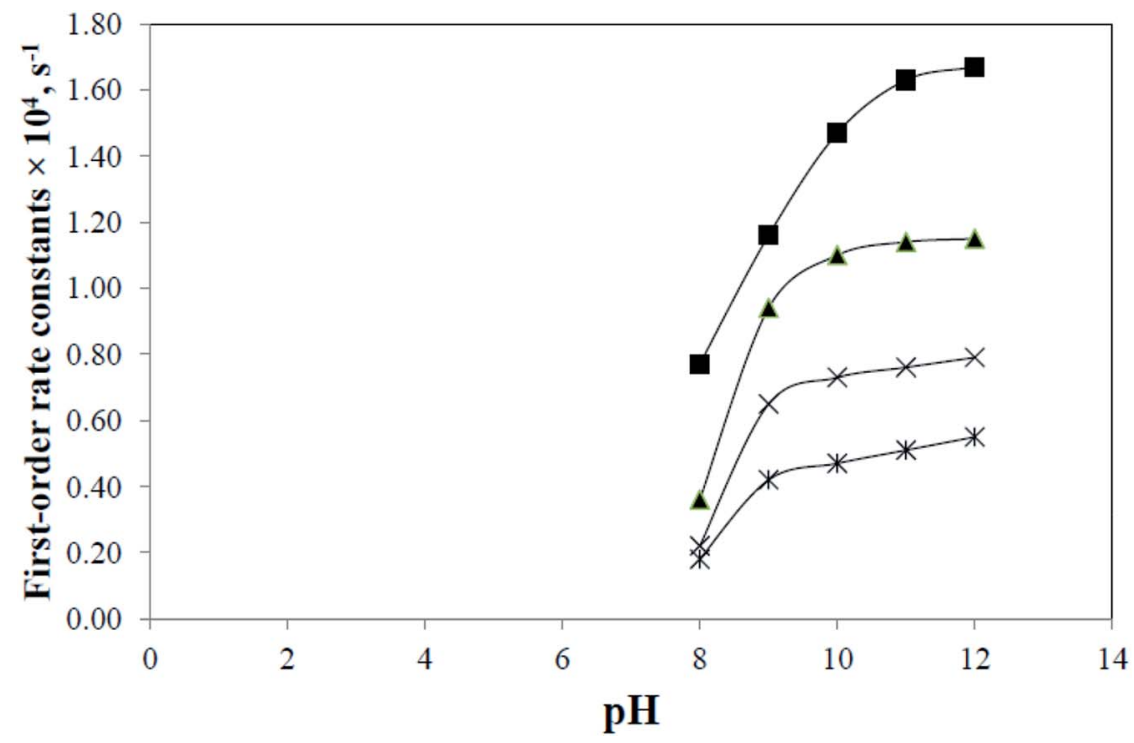

Fig. $6 k-\mathrm{pH}$ profiles for the formation of photoproducts of CMF,

$L C,(\Delta) L F,(\times)$ KA, (*) DQ. 


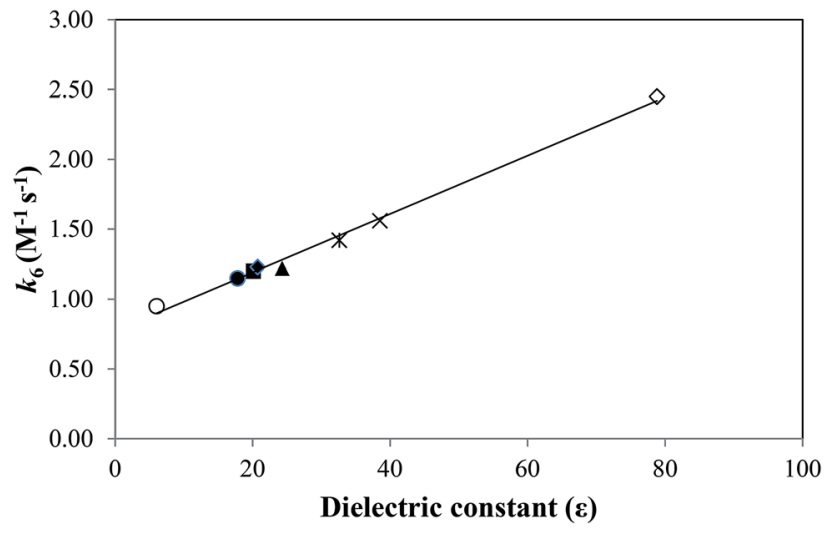

Fig. 8 Plot of $k_{\text {obs }}$ for photolysis of RF against dielectric constant: $(O)$

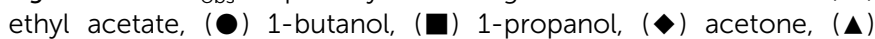
ethanol, (*) methanol, $(\times)$ acetonitrile, $(\diamond)$ water.

FMF. ${ }^{21}$ A plot of $k_{6}$ versus inverse of solvent viscosity is shown in Fig. 10. It follows a linear relation indicating that the rate of reaction is slowed down by an increase in viscosity. This is in accordance with the quenching of flavin triplet state which is inhibited with an increase in solvent viscosity. ${ }^{48}$ The rate of the reaction is suppressed by the viscosity of the solvent probably due to the involvement of a diffusion-controlled process. ${ }^{35}$ The degradation of CMF in ethyl acetate does not comply with its behaviour in other solvents. This may be due to a difference in the orientation of the side-chain in that solvent ${ }^{42}$ that would determine the rate of reaction.

\section{Effect of fluorescence}

CMF possesses an isoalloxazine nucleus similar to that of other flavins (e.g. RF, FMF and LF) and emits a yellow green fluorescence at $530 \mathrm{~nm}$ when excited at $445 \mathrm{~nm} \cdot{ }^{\mathbf{1 9 , 2 9}}$ Flavins are dipolar molecules and their fluorescence is destroyed by acid or alkali as a result of the cation or anion formation. ${ }^{66}$ To observe the effect of $\mathrm{pH}$ on the ionization behavior of the molecule, the

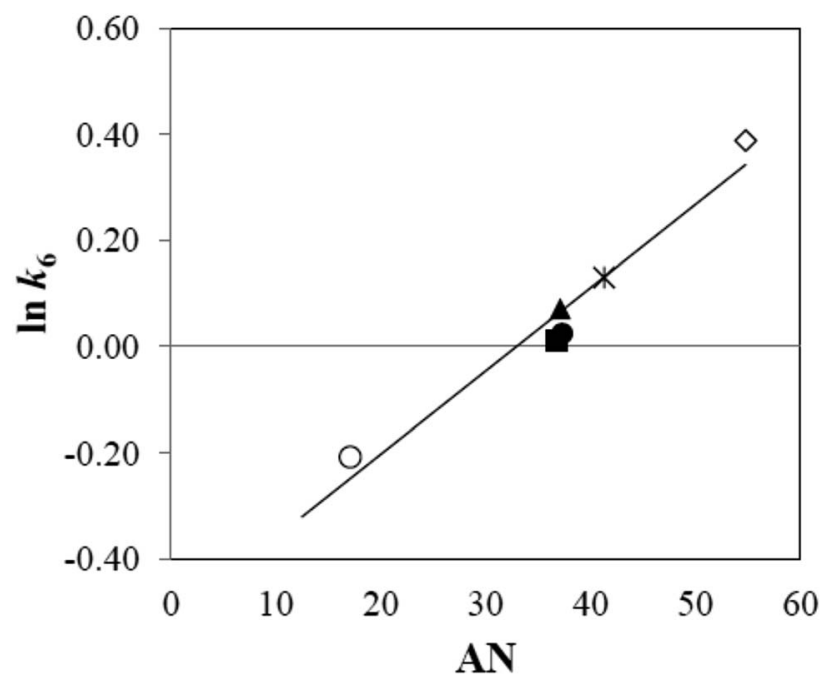

Fig. 9 Relation between In $k_{6}$ for CMF photodegradation and solvent acceptor number (AN) (symbols are as in Fig. 7).

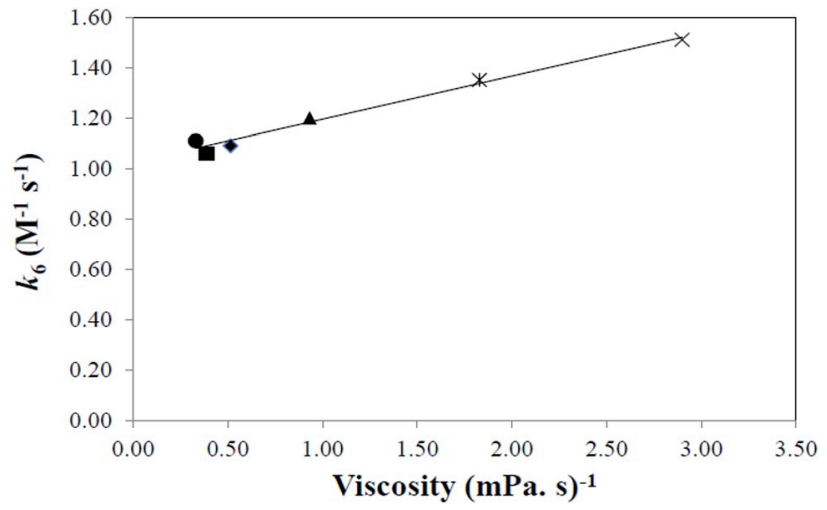

Fig. 10 Plot of $k_{6}$ for photolysis of CMF against inverse of viscosity:

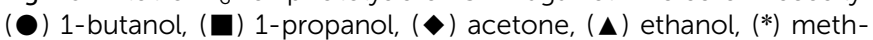
anol, $(x)$ acetonitrile.

fluorescence intensity of CMF was plotted against pH (Fig. 11). The curve indicates a slow increase in fluorescence intensity, with $\mathrm{pH}$, in acid region due to gradual deprotonation of CMF. The maximum fluorescence is exhibited in the $\mathrm{pH}$ range 7 to 8 followed by a decline due to anion formation of the molecule in alkaline region. The ionized forms of flavins are less susceptible to photolysis in aqueous solution. ${ }^{13}$ The fluorescence of CMF has also been measured in organic solvents and the relative values of fluorescence intensity and quantum yields (0.09-0.27) of CMF in aqueous and organic solvents are given in Table 7. The deactivation of the excited singlet state $\left(\mathrm{S}_{1}\right)$ is enhanced with an increase in the polarity of the solvent and hence an increase in $k_{6}$ values with a loss in fluorescence intensity of CMF in the medium has been observed.

The quantum yield of fluorescence $\left(\Phi_{\mathrm{F}}\right)$ of flavins depends on the solvent and is decreased with an increase in the polarity of the solvent. ${ }^{41}$ This is evident from the values of $\Phi_{\mathrm{F}}$ and indicates a higher photostability of flavins in less polar solvents. ${ }^{67}$ The fluorescence quantum yields may be affected by the degree of hydrogen bonding between the flavin and the solvent. ${ }^{68}$

\section{Dissociation constants of CMF}

CMF tends to ionize in acid and alkaline medium due to protonation $\left(\mathrm{N}_{10}{ }^{+} \mathrm{H}\right)$ and anion formation $\left(\mathrm{N}_{10} \mathrm{CH}_{2} \mathrm{COO}^{-}\right.$and $\left.\mathrm{N}_{3}{ }^{-}\right)$of the molecule. The $\mathrm{p} K_{\mathrm{a}}$ values of these groups have not been reported.

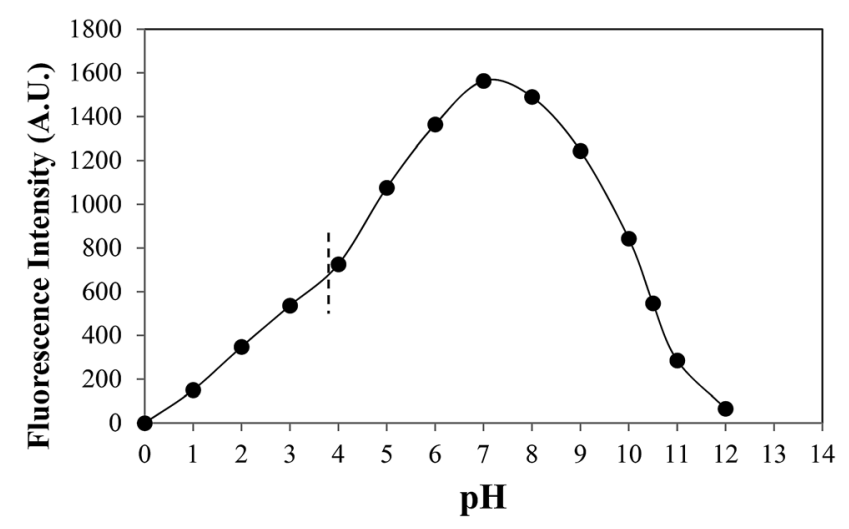

Fig. 11 A plot of fluorescence intensity of CMF against $\mathrm{pH}$. 
Table 7 Relative values of fluorescence intensity $(\% F)$ and quantum yields $\left(\Phi_{\mathrm{F}}\right)$ in $\mathrm{CMF}\left(1.0 \times 10^{-6} \mathrm{M}\right)$ and organic solvents

\begin{tabular}{lrl}
\hline Solvent & $\% F$ & $\Phi_{\mathrm{F}}$ \\
\hline Water (pH 7.0) & 48.5 & 0.13 \\
Acetonitrile & 68.6 & 0.18 \\
Methanol & 87.2 & 0.23 \\
Ethanol & 100.0 & 0.27 \\
1-Propanol & 79.8 & 0.21 \\
1-Butanol & 36.1 & 0.10 \\
Acetone & 76.3 & 0.20 \\
Ethyl acetate & 33.7 & 0.09
\end{tabular}

Since CMF possesses the nucleus same as that present in RF, the $\mathrm{p} K_{\mathrm{a}} \mathrm{S}$ of $\mathrm{N}_{10}{ }^{+} \mathrm{H}$ and $\mathrm{N}_{3}{ }^{-}$group would be similar to those of RF (1.7 and 10.2, respectively). ${ }^{62}$ However, since the fluorescence of flavins is quenched by acid and alkali ${ }^{66}$ due to ionization, the $\mathrm{p} K_{\mathrm{a}}$ of the $\mathrm{N}_{10} \mathrm{CH}_{2} \mathrm{COOH}$ group in the side-chain can be determined from the plot of fluorescence intensity versus $\mathrm{pH}$ (Fig. 11) according to the Henderson-Hasselbalch equation:

$$
\mathrm{pH}=\mathrm{p} K_{\mathrm{a}}+\log \frac{[\text { salt }]}{[\text { acid }]}
$$

Considering the fluorescence intensity-pH curve, there appears to be an inflection point around $\mathrm{pH} 4.1$ (with a fluorescence intensity corresponding to $50 \%$ ionization of the molecule). Therefore, a value of 4.1 can be considered as the $\mathrm{p} K_{\mathrm{a}}$ of the $\mathrm{N}_{10} \mathrm{CH}_{2} \mathrm{COOH}$ group of CMF. $\mathrm{N}$-heterocyclic carboxylic acids have $\mathrm{p} K_{\mathrm{a}} \mathrm{S}$ in the range of 2.9 to $4.4 .^{69,70}$ Fluorimetry has been used for the determination of the $\mathrm{p} K_{\mathrm{a}}$ values of $N$-heterocyclic bases such as 8-methylquinoline and acridine. ${ }^{71}$

\section{Quantum yields of photolysis}

The quantum yields $(\Phi)$ of the photolysis of CMF at $\mathrm{pH}$ 2.0-12.0 have been determined and are given in Tables 3 and 4 . The values of $\Phi$ in this $\mathrm{pH}$ range vary from 0.05 to 0.41 and are affected by the $\mathrm{pH}$ and reactivity of the excited triplet state of CMF. In the acid and neutral range (2.0-7.0), the $\Phi$ of formation of LC are low. In alkaline range (8.0-12.0), the $\Phi$ gradually increases since the triplet state has high reactivity in alkaline solution. ${ }^{11}$ These values show a slight decrease in the $\mathrm{pH}$ range 10-12 due to anion formation of the molecule which has low susceptibility to photolysis like those of $\mathrm{RF}^{\mathbf{1 3}}$ and FMF. ${ }^{21}$ The values of $\Phi$ of CMF are higher than those of RF photolysis in presence of divalent anions. ${ }^{72}$

LC-ESI-MS analysis. Both, standard and CMF were analyzed by LC-ESI-MS using Tof-MS spectrometry. Riboflavin has shown an $[\mathrm{M}+\mathrm{H}]^{+}$ion at $m / z 377.1440$ (calcd 377.1456) corresponding to $\mathrm{C}_{17} \mathrm{H}_{20} \mathrm{~N}_{4} \mathrm{O}_{6}$, CMF has shown $[\mathrm{M}+\mathrm{H}]^{+}$ion at $\mathrm{m} / z 301.0925$ (calcd 301.0936) corresponding to $\mathrm{C}_{14} \mathrm{H}_{12} \mathrm{~N}_{4} \mathrm{O}_{4}$. LC has shown $[\mathrm{M}+\mathrm{H}]^{+}$ion at $\mathrm{m} / \mathrm{z} 243.0872$ (calcd 243.0882) corresponding to $\mathrm{C}_{12} \mathrm{H}_{10} \mathrm{~N}_{4} \mathrm{O}_{2}$, similarly $\mathrm{LF}$ has shown $[\mathrm{M}+\mathrm{H}]^{+}$ion at $\mathrm{m} / \mathrm{z}$ 257.1033 (calcd 257.1033) corresponding to $\mathrm{C}_{13} \mathrm{H}_{12} \mathrm{~N}_{4} \mathrm{O}_{2}$. While DQ has shown $[\mathrm{M}+\mathrm{H}]^{+}$ion at $m / z 205.0971$ (calcd 205.0972) corresponding to $\mathrm{C}_{16} \mathrm{H}_{19} \mathrm{~N}_{2} \mathrm{O}_{2}$. The peak for $\beta$-KA was not found using positive ionization mode which could probably appear in negative ionization mode of MS. Extracted ion chromatograms of all the mentioned compounds along with their high resolution masses (Fig. 1-5) are given in ESI. $\dagger$

\section{Mode of photolysis}

CMF undergoes photolysis to form LC in acid solution. The kinetic data indicate that the transformation of CMF to LC takes place by a second-order reaction. This is in accordance with the photolysis of FMF which also yields LC in acid solution. ${ }^{21}$ The formation of LC and LF in alkaline solution has been found to take place by parallel first-order reactions as observed in the case of FMF. ${ }^{17-19,21}$ Therefore, an analogous scheme for the photolysis of CMF is proposed (Scheme 2).

In acid solution CMF is promoted to the excited singlet state, ${ }^{1}[\mathrm{CMF}]^{*}$, by the absorption of a photon of light (eqn (12)) which may be deactivated to the ground state, ${ }^{1}[\mathrm{CMF}]$ (eqn (13)), or is converted to triplet state, ${ }^{3}[\mathrm{CMF}]^{*}$ (eqn (14)) by intersystem crossing (ISC). ${ }^{3}[\mathrm{CMF}]^{*}$ may return to the ground state (eqn (15)) or on interaction with a ground state molecule is photolyzed to $\mathrm{LC}$ and $\mathrm{CH}_{3} \mathrm{COOH}$ (eqn (16)). Alternatively it may give rise to a cationic $\left[\mathrm{CMF}^{\cdot+}\right]$ and an anionic $\left[\mathrm{CMF}^{--}\right]$radical (eqn (17)), which on losing or accepting a proton form a neutral radical [CMF ${ }^{*}$ (eqn (18)) and a semiquinone radical [CMFH ${ }^{*}$ (eqn (19)), respectively, as described previously in the case of other flavins. ${ }^{48}$ Two semiquinone radicals

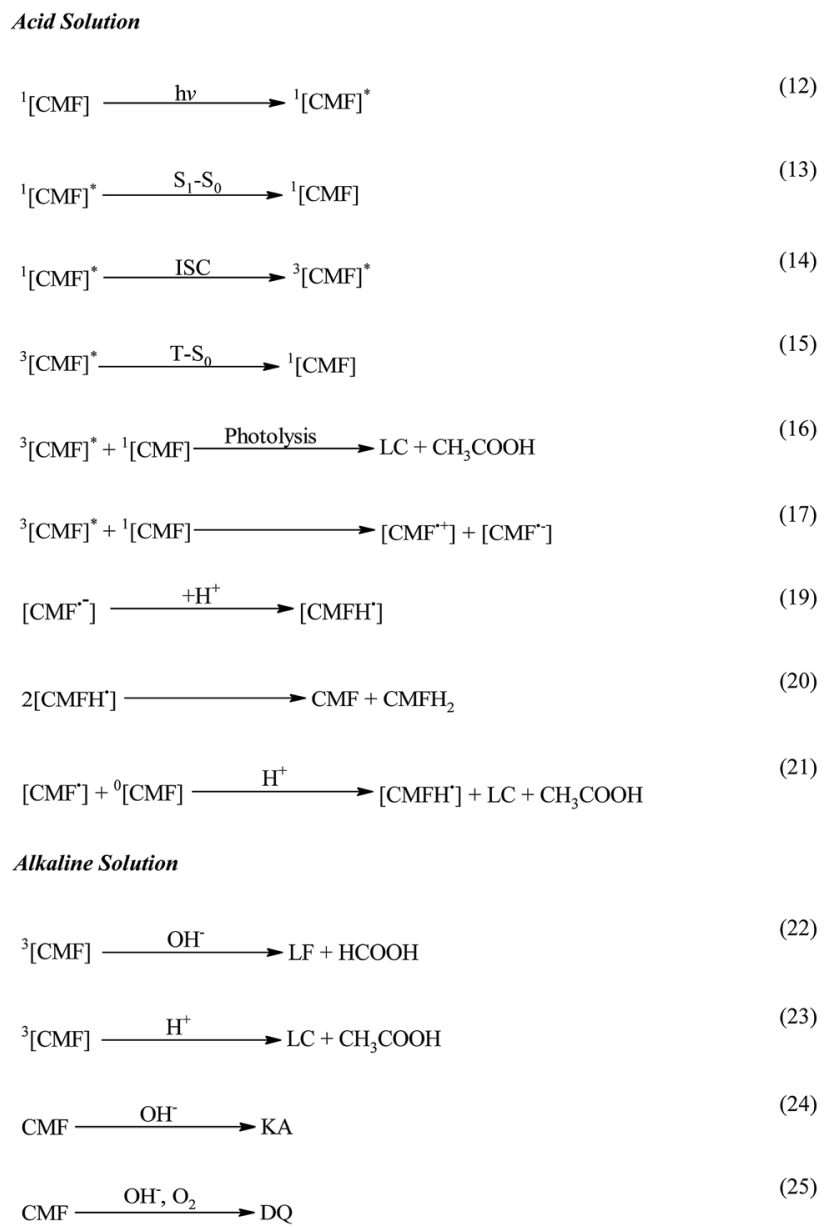

Scheme 2 
disproportionate $^{73}$ to give a neutral molecule and a dihydro intermediate product $\left[\mathrm{CMFH}_{2}\right]$ (eqn (20)) similar to that predicted by Berdicka $^{74}$ in the photolysis of RF and suggested by Ahmad et al. eqn (21) in the photolysis of FMF. The neutral radical reacts with a neutral molecule and they are degraded to a semiquinone radical, LC and $\mathrm{CH}_{3} \mathrm{COOH}$ (eqn (22)).

In the alkaline solution the photolysis of CMF takes place by hydrolytic degradation as reported in the case of FMF. ${ }^{17,18,21} \mathrm{An}$ increase in rate at $\mathrm{pH}$ 8.0-10.0 could be attributed to configurational changes and greater reactivity of the flavin triplet state to alkaline hydrolysis. ${ }^{11}$ This leads to the formation of LF and formic acid (eqn (22)) and LC and acetic acid (eqn (23)). CMF is also degraded by hydrolytic cleavage of isoalloxazine ring in alkaline solution to yield KA (eqn (24)) and DQ (eqn (25)). ${ }^{29}$

\section{Conclusions}

CMF is an intermediate product in the photolysis of RF. On visible irradiation the side-chain of CMF is removed to form LC in acid solution and LC and LF in alkaline solution. The isoalloxazine ring of the molecule is also cleaved in alkaline solution to yield quinoxaline derivatives. In organic solvents $\mathrm{CMF}$ is photodegraded to LC only. CMF is degraded in acid solution and organic solvents by second-order kinetics and in alkaline solution by simultaneous first-order kinetics. The rate constants for the formation of LC and LF in alkaline solution are higher than those of the quinoxaline derivatives. CMF degradation is increased in alkaline solutions due to the enhanced reactivity of the excited triplet state. The photostability of CMF is greater in organic solvents than in the aqueous solution due to a decrease polarity of the medium. The photoproducts of CMF have been identified chromatographically and determined spectrofluorimetrically in degraded solutions. The quantum yields of fluorescence and photolysis of CMF have been reported. A scheme for photodegradation reactions of $\mathrm{CMF}$ in aqueous and organic solvent is presented.

\section{Conflicts of interest}

There are no conflicts to declare.

\section{Acknowledgements}

The authors gratefully acknowledge Higher Education Commission of Pakistan for financial support to conduct this study through a grant (Research Project \# 20-3968) to Iqbal Ahmad. They Thank Professor Alfons Penzkofer University of Regensburg, Germany and Professor Marek Sikorski, Adam Mickiewicz University of Poznan, Poland for helpful discussions.

\section{References}

1 R. S. Rivlin, in Handbook of Vitamins, ed. J. Zempleni, R. B. Rucker, D. B. McCormick and J. W. Suttie, Taylor \& Francis, CRC Press, Boca Raton, FL, 2007, pp. 233-251.

2 V. Massey, Biochem. Soc. Trans., 2000, 28, 283-296.
3 P. F. Heelis, in Chemistry and Biochemistry of Flavoenzymes, ed. F. Muller, CRC Press, Boca Raton, FL, 1991, pp. 171-193.

4 I. Ahmad and F. H. M. Vaid, in Flavins: Photochemistry and Photobiology, ed. E. Silva and A. M. Edwards, The Royal Society of Chemistry, Cambridge, 2006, pp. 13-40.

5 M. A. Sheraz, S. H. Kazi, S. Ahmed, Z. Anwar and I. Ahmad, Beilstein J. Org. Chem., 2014, 10, 1999-2012.

6 Z. Anwar and I. Ahmad, in Advances in Medicine and Biology, ed. L. V. Berhardt, Nova Science Publishers, USA, 2017, pp. 139-180.

7 British Pharmacopoeia, Her Majesty's Stationary Office, London, UK, 2016.

8 United States Pharmacopeia 29, United States Pharmacopoeial Convention, Rockville, MD, 2016.

9 E. C. Smith and D. E. Metzler, J. Am. Chem. Soc., 1963, 85, 3285-3288.

10 G. E. Treadwell, W. L. Cairns and D. E. Metzler, J. Chromatogr., 1968, 35, 376-388.

11 W. L. Cairns and D. E. Metzler, J. Am. Chem. Soc., 1971, 93, 2772-2777.

12 I. Ahmad and H. D. Rapson, J. Pharm. Biomed. Anal., 1990, 8, 217-223.

13 I. Ahmad, Q. Fasihullah, A. Noor, I. A. Ansari and Q. N. Ali, Int. J. Pharm., 2004, 280, 199-208.

14 I. Ahmad, S. Ahmed, M. A. Sheraz, F. H. M. Vaid and I. A. Ansari, Int. J. Pharm., 2010, 390, 174-182.

15 I. Ahmad, Z. Anwar, K. Iqbal, S. A. Ali, T. Mirza, Ad. Khurshid, Aq. Khurshid and A. Arsalan, AAPS PharmSciTech, 2014, 15, 550-559.

16 I. Ahmad, Z. Anwar, S. Ahmed, M. A. Sheraz, R. Bano and A. Hafeez, AAPS PharmSciTech, 2015, 16, 1122-1128.

17 P. S. Song, E. C. Smith and D. E. Metzler, J. Am. Chem. Soc., 1965, 87, 4181-4184.

18 I. Ahmad, H. D. Rapson, P. F. Heelis and G. O. Phillips, J. Org. Chem., 1980, 45, 731-733.

19 I. Ahmad, T. Mirza, Z. Anwar, M. A. Ejaz, M. A. Sheraz and S. Ahmed, Spectrochim. Acta, Part A, 2018, 205, 540-550.

20 I. Ahmad, Q. Fasihullah and F. H. M. Vaid, Photochem. Photobiol. Sci., 2006, 5, 680-685.

21 I. Ahmad, T. Mirza, K. Iqbal, S. Ahmed, M. A. Sheraz and F. H. M. Vaid, Aust. J. Chem., 2013, 66, 579-585.

22 C. Fukamachi and Y. Sakurai, J. Vitaminol., 1955, 1, 217-220. 23 S. Svobodova-Leblova, J. V. Kostir and I. M. Hais, J. Chromatogr., 1964, 14, 451-455.

24 P. F. Heelis, Chem. Soc. Rev., 1982, 11, 15-39.

25 P. Hemmerich, Fortschr. Chem. Org. Naturst., 1976, 33, 451527.

26 I. Ahmad, A. E. Beg and S. M. S. Zoha, Pak. J. Pharm. Sci., 1973, 2, 84-91.

27 D. A. Wadke and D. E. Guttman, J. Pharm. Sci., 1966, 55, 1088-1092.

28 D. A. Wadke and D. E. Guttman, J. Pharm. Sci., 1966, 55, 1363-1368.

29 T. Mirza, Z. Anwar, M. A. Ejaz, S. Ahmed, M. A. Sheraz and I. Ahmad, Luminescence, 2018, 33, 1314-1325.

30 E. S. Amis and J. F. Hinton, Solvent Effect on Chemical Phenomena, Academic Press, New York, 1973. 
31 M. H. Abraham, Pure Appl. Chem., 1985, 57, 1055-1064.

32 C. Reichardt, Solvents and Solvent Effects in Organic Chemistry, VCH Publishers, New York, 1988, pp. 7-64.

33 H. Heitele, Angew. Chem., Int. Ed. Engl., 1993, 32, 359-377.

34 E. Buncel, R. A. Stairs and H. Wilson, The Role of the Solvent in Chemical Reactions, Oxford University Press, New York, 2003.

35 N. J. Turro, V. Ramamurthy and J. C. Scaierno, Modern Molecular Photochemistry of Organic Molecules, University Science: Sausalito, 2010, pp. 469-474.

36 K. A. Connors, G. L. Amidon and V. J. Stella, Chemical Stability of Pharmaceuticals A Handbook for the Pharmacist, Wiley, New York, 1986, pp. 38-41.

37 J. T. Carstensen, in Drug Stability Principles and Practices, ed. J. T. Carstensen and C. T. Rhodes, Marcel Dekker, New York, 2000, pp. 58-60, 65-67.

38 S. Yoshioka and V. J. Stella, Stability of Drugs and Dosage Forms, Kluwer Academic/Plenum Publishers, New York, 2000, pp. 102-104.

39 G. K. Jain, F. Jain, F. J. Ahmad, R. K. Khar, L. Lachman, P. Deluca and M. G. Akers, in The Theory and Practice of Industrial Pharmacy, ed. R. K. Kharm, S. P. Vyas, F. J. Ahmad and G. K. Jain, CBS Publishers \& Distributors, India, 2009, pp. 1036-1072.

40 P. J. Sinko, in Martin's Physical Pharmacy and Pharmaceutical Sciences, Lippincott Williams \& Wilkins, Philadelphia, 2006, pp. 413-416.

41 J. Koziol, Photochem. Photobiol., 1966, 5, 55-62.

42 W. E. Kurtin, M. A. Latino and P. S. Song, Photochem. Photobiol., 1967, 6, 247-259.

43 W. M. Moore and R. C. Ireton, Photochem. Photobiol., 1977, 25, 347-356.

44 M. Insinska-Rak, A. Golczak and M. Sikorski, J. Phys. Chem., 2012, 116, 1199-1207.

45 I. Ahmad and Q. Fasihullah, Pak. J. Pharm. Sci., 1991, 4, 2126.

46 E. Sikorski, D. R. Worrall, J. I. Bourdelande and M. Sikroski, Pol. J. Chem., 2003, 77, 65-73.

47 V. Szezesma and J. Koziol, Physiochemical Properties and Functions, in Flavins and Flavoproteins, ed. W. Ostrowski, Polish Scientific Publishers, Warsaw, 1977, pp. 117-126.

48 I. Ahmad and G. Tollin, Biochemistry, 1981, 20, 5925-5928.

49 P. Zirak, A. Penzkofer, T. Mathes and P. Hegemann, Chem. Phys., 2009, 358, 111-122.

50 A. R. Surrey and F. C. Nachod, J. Am. Chem. Soc., 1951, 73, 2336-2338.
51 H. T. Miles, P. Z. Smyrniotis and E. R. Stadtman, J. Am. Chem. Soc., 1959, 81, 1945-1951.

52 C. G. Hatchard and C. A. Parker, Proc. R. Soc. London, Ser. A, 1956, 235, 518-536.

53 P. Zirak, A. Penzkofer, T. Schiereis, P. Hegemann, A. Jung and I. Schlichting, Chem. Phys., 2005, 315, 142-154.

54 P. Zirak, A. Penzkofer, P. Hegemann and T. Mathes, Chem. Phys., 2007, 335, 15-27.

55 A. Tyagi and A. Penzkofer, J. Photochem. Photobiol., A, 2010, 215, 108-117.

56 A. T. R. Williams, S. A. Winfield and J. N. Miller, Analyst, 1983, 108, 1067-1071.

57 G. Weber and F. H. J. Teale, Trans. Faraday Soc., 1957, 55, 646-655.

58 H. H. Fall and H. G. Petering, J. Am. Chem. Soc., 1956, 78, 377-381.

59 I. Ahmad, S. Ahmed, M. A. Sheraz and F. H. M. Vaid, J. Photochem. Photobiol., B, 2008, 93, 82-87.

60 A. Frost and R. G. Pearson, Kinetics and Mechanism, John Wiley, New York, 1964, pp. 150-155, 160-162.

61 I. Ahmad, Z. Anwar, S. A. Ali, K. A. Hasan, M. A. Sheraz and S. Ahmed, J. Photochem. Photobiol., B, 2016, 157, 113-119.

62 The Merck Index, ed. M. J. O'Neil, Merck \& Co. Inc., Rahway, NJ, USA, 13th edn, 2013.

63 C. H. Suelter and D. E. Metzler, Biochim. Biophys. Acta, 1960, 44, 23-33.

64 V. Guttman, The Donor-Acceptor Approach to Molecular Interactions, Plenum Press, New York, 1978.

65 R. Schmidt and V. N. Sapunov, Non-Formal Kinetics, Verlag Chemie, Weinheim, Germany, 1982, pp. 123-154.

66 G. Weber, Biochem. J., 1950, 47, 114-121.

67 J. Koziol, Photochem. Photobiol., 1966, 5, 41-54.

68 K. Yagi, N. Ohisi, K. Nishimoto, J. D. Choi and P. S. Song, Biochemistry, 1980, 19, 1553-1557.

69 A. Albert and E. P. Serjeant, Non-Formal Kinetics, John Wiley \& Sons Inc., New York, 1962, p. 127.

70 W. F. Gum Jr and M. M. Joullie, J. Org. Chem., 1965, 30, 39823985.

71 L. S. Rosenberg, J. Simons and S. G. Schulman, Talanta, 1979, 26, 867-871.

72 F. H. M. Vaid, W. Gul, A. Faiyaz, Z. Anwar, M. A. Ejaz, S. Zahid and I. Ahmad, J. Photochem. Photobiol., A, 2019, 371, 59-66.

73 I. Ahmad, M. A. Cussanovich and G. Tollin, Proc. Natl. Acad. Sci. U. S. A., 1981, 68, 6724-6728.

74 R. Berdicka, Collect. Czech. Chem. Commun., 1949, 14, 130144. 